PATIENT PAGE

Section Editors

David C. Spencer, MD

Steven Karceski, MD

Efstathia Tzatha, MD

Steven C. Karceski, MD

\title{
Responsive neurostimulation for the treatment of seizures that do not respond to medication
}

In the last 18 years, 12 new antiseizure medications have been discovered. Although there are more medications, there have been no medicines that are clearly better than the older ones. To be clear, the newer medicines do not seem to be any more effective at stopping seizures than the older ones. Studies have shown that about one-third of people with epilepsy have seizures that do not respond to antiseizure medication. A doctor will call the person's seizures refractory if they have tried 2 or more antiseizure medications, and their seizures have not stopped.

Although the newer medicines do not seem to be more effective than the older ones, generally speaking, they seem to cause fewer side effects. Despite this, many patients have difficulty tolerating the high doses that are needed to control their seizures. Because of this, there has been increasing interest in devices that can help to control seizures. One device, the vagus nerve stimulator (VNS), is already available. It was approved for use by the US Food and Drug Administration (FDA) in 1997 for the treatment of refractory epilepsy. Other devices are being studied now, including the responsive cortical stimulator (also known as the responsive neurostimulator or RNS), as discussed in this Patient Page.

WHAT DID THE RESEARCHERS DO? In their study, "Responsive cortical stimulation for the treatment of medically intractable partial epilepsy," Dr. Morrell et al. ${ }^{1}$ studied a new kind of brain stimulator for the treatment of refractory seizures. Their idea was simple: to study a device that would respond to a person's seizures. In other words, is it possible to develop a device that works only when needed? If so, is the implantable neurostimulator both safe and effective?

In order to do this, the study was carried out at 32 epilepsy centers around the country. It took 3 years to complete the study. The people who were implanted were adults with partial epilepsy whose seizures did not respond to medications.

The device that they used is completely different from the one that is currently available. The RNS sends small electrical impulses to the brain. If these impulses are sent when the brain is having a seizure, the seizure may stop. The RNS is "taught" how to recognize a person's electrical seizure pattern. When it detects this, it automatically sends the small electrical impulse to stop the seizure in progress. The theory is that the RNS would recognize the start of the seizure, and safely send the impulse to stop the seizure. This method of treatment is called responsive cortical stimulation (or responsive neurostimulation).

The researchers selected patients very carefully for the study. They enrolled 191 adult patients with partial onset seizures (seizures that start in a specific area of the brain). All patients had tried 2 or more seizure medications, but were still having seizures. In fact, they were having more than 3 disabling seizures per month. In addition, these people had many medical tests, like MRI and EEG. The testing confirmed that they had partial epilepsy, and also showed the area (or areas) of brain where the seizures were starting.

A total of 191 patients were selected to be implanted with the RNS. There were an equal number of men and women. The average age of the patients was 35 years (between the ages of 18 and 70). They had epilepsy for an average of 20 years. One-third of them had already had unsuccessful brain surgery or VNS implantation.

After enrolling in the trial, patients were implanted with an RNS. To allow for healing, the doctors waited 1 month before starting treatment with the RNS. They split the patients into 2 groups. Onehalf of the group had their device turned "on." They were called the "treatment group." In the other half, the device was left "off." This group was called the "sham group."

I know that this seems unfair to the sham group. They had surgery to implant the RNS, but did not have treatment for several months. Although it seems unfair, it is a necessary part of a trial like this one. In order to know if a treatment works, and is safe, the treatment must be compared to placebo. After a period of time, the treatment group is compared to the sham group.

First, the investigators looked to see how much the seizures responded to treatment. They looked at how each group's seizures changed, and compared this to the number of seizures that were happening before the RNS was implanted. Second, they compared the kind and number of problems that each 
group had. The patients were followed like this for 3 months.

After 3 months, all patients had their devices "turned on." In other words, this is when treatment for the sham group started. All patients were then treated for another 21 months. The investigators very carefully watched changes in seizures the whole time. They looked for changes in seizures that might take a while to be noticed.

Patients were also asked to keep track of quality of life and mood. Patients had to fill out forms several times through the treatment. They answered questions before the device was implanted, at the end of 3 months, and again at 1 year and 2 years after the implantation.

WHAT WERE THE RESULTS? The researchers found that during the first 3 months of treatment that the seizures were reduced in the treatment group (by 38\%) when compared to the sham group (by $17 \%)$. There was no difference between the 2 groups in adverse events. During the next 21 months (the open-label period), both groups' seizures got better. Remember, after the first 3 months, everyone was treated with RNS. In both groups, the seizure reduction rate was $43 \%$ at the end of the first year and reached $46 \%$ at the end of the second year.

There were also improvements in overall quality of life. There was no worsening of mood. Memory, language, and other measures of neuropsychological function were the same or improved. More specifically, patients reported improvements in language, memory, attention and concentration, work, driving, social function, and seizure worry.
Careful analysis also showed that the responsive stimulation worked in all areas of brain that were tested. Even if a person had 1 or 2 seizure-onset areas, the device still worked. It was effective in people who had prior brain surgery. It also worked in people who had already tried other electrical stimulation devices like the VNS.

WHY IS THE STUDY IMPORTANT? This is the first time that a device like this has been studied. Although the current device helps to decrease seizures, it does not respond to seizures automatically. The RNS is designed to identify a person's seizures, and to send a small impulse to the brain to stop seizures that are happening at that instant. This study was very important because it showed that the RNS can effectively reduce seizures in adult patients who have partial-onset medically intractable epilepsy.

In addition to effectiveness, the study looked at the safety of RNS. There is a known risk to implanting electrodes around (and into) the brain. However, the RNS was found to be as safe as other implanted brain devices. Infection can occur with any surgery, including surgery where a medical device is placed. Serious infection due to RNS was about the same or less than what has been reported with other implanted brain devices.

The advantage of RNS is that the treatment is specific to the person. The system senses and records each patient's abnormal seizure activity and then provides stimulation to stop the seizures. Given the results of the trial, RNS provides a new treatment option for adults with medically intractable partial epilepsy. 
Section Editors

David C. Spencer, MD

Steven Karceski, MD

\section{About epilepsy}

WHAT IS EPILEPSY? Epilepsy is a very common chronic neurologic condition. It affects $1 \%-2 \%$ of the population, which means that it affects $4-8$ million Americans. The American Academy of Neurology defines epilepsy as a brain disorder in which nerve cells in the brain sometimes send abnormal signals to each other. In epilepsy, the normal pattern of brain activity is interrupted, causing strange sensations, emotions, and changes in behavior. Someone watching the seizure may see shaking (convulsions), jerking or stiffening of the muscles (muscle spasms), confusion, and loss of consciousness. Epilepsy is a disorder with many causes: from brain damage to abnormal brain development.

WHAT IS PARTIAL EPILEPSY? Broadly, seizures can be classified as either generalized or focal (partial is another term for focal). A partial seizure is one that begins from a specific area of the brain. This is different from a generalized seizure, where the seizure essentially starts "all over the brain" or "everywhere all at once." Partial seizures are divided into different types. Partial seizures are called complex if they cause loss of awareness. When the person remains awake and aware of what is going on, the partial seizure is called simple. It should be noted that even though the partial seizures start at a specific area of the brain, they can sometimes spread to other brain areas. When they spread to the whole brain, they look just like generalized seizures (with stiffening of the arms and legs, and shaking all over).

TREATMENT Even though epilepsy has been recognized as a disease since the ancient times, it was not until 1857 that the first antiepileptic medication was discovered. Over the next 100 years, 9 medications were found to help control seizures. In the last 18 years, the discovery rate is much higher, with 12 new medications approved for use by the FDA. Although there are many new medicines, approximately $30 \%$ of the people still have seizures that do not stop with medication. In addition, many people do not "like" their medication because of side effects.

In 1997, the FDA approved the first implantable device, called VNS, as added therapy for refractory partial seizures. The VNS sends a small electrical impulse to a nerve in the neck called the vagus nerve.
This impulse travels back to the brain, where it helps to reduce or stop seizures. With this device, about $5 \%-6 \%$ of patients stop having seizures, and up to $70 \%$ find that their seizures are reduced by $50 \%$ or more.

In addition to medications and devices like the VNS, brain surgery can help stop seizures in people with partial epilepsy. Though effective, brain surgery carries a risk of bleeding, stroke, and infection. Though rare, these problems can sometimes cause lifelong neurologic problems.

With the success of deep brain stimulation for treatment of movement disorders like Parkinson disease and essential tremor, brain stimulation has received new attention as possible treatment for epilepsy. RNS aims to suppress seizures by delivering stimulation directly to the brain. Instead of automatic stimulation like the VNS, RNS responds to the person's seizures. In other words, it is active only when needed. Responsive stimulation is also very specific. In contrast to medicines, with the possibility of side effects, electrical stimulation can be aimed to the specific brain regions involved in the seizure. ${ }^{2}$ In their study, Morrell et al. showed that the responsive neurostimulator can help partial seizures even if the person has already tried brain surgery or VNS.

Many research studies on new treatments for epilepsy are currently underway. As new medications and implantable devices are being discovered, we are moving closer to our goal: better seizure control and few (or no) side effects.

\section{FOR MORE INFORMATION}

American Academy of Neurology patients and caregivers site http://patients.aan.com

Citizens United for Research in Epilepsy

http://www.CUREepilepsy.org

Epilepsy Foundation

http://www.epilepsyfoundation.org

Epilepsy Institute

http://www.epilepsyinstitute.org

\section{REFERENCES}

1. Morrell MJ, RNS System in Epilepsy Study Group. Responsive cortical stimulation for the treatment of medically intractable partial epilepsy. Neurology 2011;77:1295-1304.

2. Sun FT, Morrell MJ, Wharen RE Jr. Responsive cortical stimulation for the treatment of epilepsy. Neurotherapeutics 2008;5:68-74. 


\section{Neurology}

\section{Responsive neurostimulation for the treatment of seizures that do not respond to medication}

Efstathia Tzatha and Steven C. Karceski

Neurology 2011;77;e79-e81

DOI 10.1212/WNL.0b013e31823303fa

This information is current as of September 26, 2011

\section{Updated Information \&} Services

References

Subspecialty Collections

Permissions \& Licensing

Reprints including high resolution figures, can be found at: http://n.neurology.org/content/77/13/e79.full

This article cites 2 articles, 1 of which you can access for free at: http://n.neurology.org/content/77/13/e79.full\#ref-list-1

This article, along with others on similar topics, appears in the following collection(s): All Epilepsy/Seizures http://n.neurology.org/cgi/collection/all_epilepsy_seizures

Information about reproducing this article in parts (figures,tables) or in its entirety can be found online at:

http://www.neurology.org/about/about_the_journal\#permissions

Information about ordering reprints can be found online:

http://n.neurology.org/subscribers/advertise

Neurology ${ }^{\circledR}$ is the official journal of the American Academy of Neurology. Published continuously since 1951 , it is now a weekly with 48 issues per year. Copyright Copyright $@ 2011$ by AAN Enterprises, Inc.. All rights reserved. Print ISSN: 0028-3878. Online ISSN: 1526-632X.

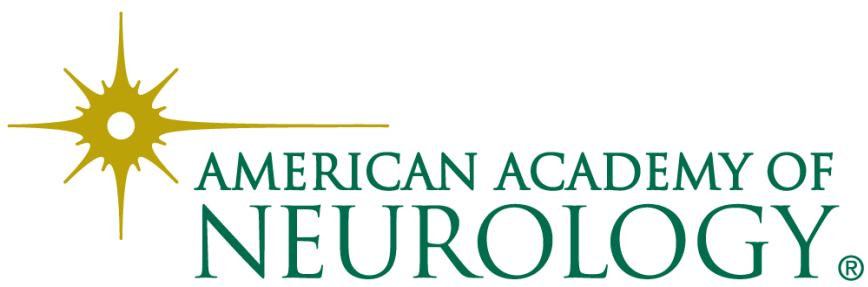

